\title{
ANALISIS DAN PERANCANGAN E-COMMERCE MENGGUNAKAN CONTENT MANAGEMENT SYSTEM WORDPRESS PADA KAYRA NU HIJAB
}

\author{
Humisar Hasugian ${ }^{1 *}$, Firmanto ${ }^{2}$ \\ ${ }^{12}$ Fakultas Teknologi Informasi, Program Studi Sistem Informasi, Universitas Budi Luhur, Jakarta, Indonesia

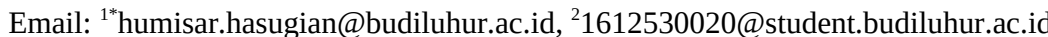 \\ (* : coressponding author)
}

\begin{abstract}
Abstrak-Wabah Covid-19 mengharuskan setiap orang dan badan usaha untuk merubah gaya hidup agar tetap bertahan, dampak yang paling terlihat adalah hampir semua kegiatan usaha dilakukan secara online, badan usaha yang tetap bertahan dengan gaya lama akan ketinggalan dan bahkan gulung tikar. Penjualan produk pada Kayra Nu Hijab mengalami dampak dimana semakin hari penjualan semakin menurun, hal ini disebabkan karena pelanggan kesulitan untuk mendapatkan informasi produk dan ketersediaan stok, dan kesulitan melakukan pesanan. Solusi yang dirancang untuk mengatasi masalah tersebut adalah merancang sebuah website e-commerce memanfaatkan management system wordpress dengan tambahan plugin woocommerce dan analisa bisnis menggunakan bisnis model canvas. Hasil penelitian ini berupa website yang dapat diakses secara online sehingga memudahkan pelanggan pada saat melihat informasi produk, ketersediaan stok, dan dapat melakukan pesanan secara langsung tanpa datang langsung ke toko, hasil luaran penelitian ini diharapkan dapat meningkatkan penjualan toko dan memperluas jangkauan pasar.
\end{abstract}

Kata Kunci: E-commerce, Management System, Kayra Nu Hijab, bisnis model canvas, Toko Online

\begin{abstract}
The COVID-19 pandemic forces every person and business entity to change their lifestyle in order to survive. The most impact is that all business activities are now turned online. The company that is still persist with the old style will fall behind and even go bankrupt. The impact is also experienced by the product sales of Kayra Nu Hijab when day by day the sales have been decreasing due to the customers have difficulty finding product information, its stock availability, and also difficulty for placing an order. to resolve the issues, an e-commerce website was designed using a content management system Wordpress witd woocommerce plugin and business analysis using a business canvas model. The result is in the form of a website that can be accessed online, making it easier for customers to view product information and its stock availability, and to place orders online without having to come directly to the store. the results of this research can increase the sales and expand the market opportunities.
\end{abstract}

Keywords: E-Commerce, Management System, Kayra Nu Hijab, Business Canvas Model, Online Shop.

\section{PENDAHULUAN}

Teknologi Informasi mempunyai peranan penting diberbagai bidang salah satunya bidang ekonomi khususnya dalam pemasaran produk. Belakangan ini banyak badan usaha menggunakan e-commerce untuk mendukung kegiatan usaha seperti memudahkan dalam mengelola usaha, meminimalkan biaya operasional perusahaan, mempermudah pengaturan produk, pemasaran produk lebih mudah dikenal masyarakat luas dan mempermudah dalam penyajian laporan-laporan yang di butuhkan. Kemudahan yang dirasakan dari pembeli adalah pembeli dimudahkan dalam melihat produk-produk, melihat informasi produk, memesan produk serta melakukan pembayaran dilakukan secara online. Dengan menggunakan E-commerce membantu perusahaan untuk melakukan transaksi penjualan produk secara online 24 jam dalam sehari dan 7 hari dalam seminggu.

Kayra Nu Hijab adalah toko yang menjual hijab, gamis dan produk fashion muslim lainnya. Saat ini semua proses penjualan di Kayra Nu Hijab masih dilakukan secara langsung dan melalui media sosial Instagram dan Facebook. Dengan kata lain bahwa pembeli harus datang langsung secara fisik ke toko atau berkomunikasi melalui media sosial untuk melakukan pemesanan produk yang diinginkan atau sekedar untuk menanyakan informasi produk yang diinginkan. Masalah yang ditemukan adalah (a) pemilik usaha tidak bisa mendapatkan laporan-laporan penjualan secara cepat dikarenakan pembuatan laporan masih manual dan menunggu proses rekapitulasi data transaksi penjualan. (b) Pembeli harus menghubungi pihak toko agar mendapatkan informasi detil produk yang dijual seperti stok dan jenis-jenis produk yang dijual. (c) Kurangnya jangkauan pemasaran dan promosi produk, sehingga pembeli yang membeli hanya berasal dari wilayah sekitar toko. Dan tujuan penelitian ini adalah untuk menganalisis, merancang dan membangun sistem e-commerce berbasis website pada Kayra $\mathrm{Nu}$ Hijab guna membantu proses penjualan, pelaporan dan memperluas jangkauan pemasaran pada Kayra Nu Hijab. Adapun batasan permasalahan adalah (a) e-commerce menggunakan konsep Business to Customer (B2C)[1]. (b) Fasilitas yang dibuat meliputi proses penjualan, proses pembayaran, proses pengiriman sampai dengan proses 
pembuatan laporan. (c) Pembuatan e-commerce menggunakan Content Management System (CMS)[2] WordPress. (d)Implementasi Search Engine Optimization (SEO)[3] menggunakan fitur plug-in Yoast SEO, penerapan teknik SEO untuk mendapatkan hasil yang paling optimal di mesin pencari Google, mendapatkan traffic pengunjung. (e) Penerapan strategi pemasaran untuk menarik perhatian pengunjung website agar membeli produk. Dalam penelitian ini penulis memilih topik pembahasan transaksi penjualan produk pada toko Kayra $\mathrm{Nu}$ Hijab yang kemudian akan dibuatkan model analisis dan perancangan e-commerce wordpress dengan tambahan plug in woocommerce, sesuai dengan permasalahan yang dihadapi user dan diberi judul Analisis dan Perancangan E-Commerce Menggunakan Content Management System Wordpress Pada Kayra Nu Hijab.

Studi literatur yang penulis jadikan referensi dalam penelitian ini antara lain Menurut Erick Fernando, Abdul Rahim, Nur Azmi Yati (penulis pertama), Membahas tentang perancangan E-commerce untuk toko I’M Collection WTC yang berlokasi di jambi untuk mempermudah aktivitas transaksi penjualan dan pengolahan data penjualan, serta memberikan informasi kepada pelanggan, Oktober 2017[4]. penelitian Syahriani juga membahas tentang rancangan dan penerapan sistem informasi e-commerce untuk mempermudah pendataan data penjualan dan pemasaran produk Every Baby Shop, Agustus 2017[5]. Andy Prasetyo Utomo, Diana Laily Fithri (penulis pertama), Fajar Nugraha Membahas tentang implementasi teknologi informasi dalam dunia pemasaran berbasis e-commerce, guna meningkatkan penjualan dan memperluas jangkauan promosi pada KUB Bordir Kurnia Kudus, November 2017[6].

Pada penelitian ini proses pengumpulan data melalui interview dan observasi di toko dan melakukan analisa permasalahn dengan alat bantu fishbone diagram, merancang Business Model Canvas (BMC)[7] sesuai dengan kebutuhan bisnis terkini, merancang fungsionalitas sistem dengan menggunakan use case diagram[8] sesuai dengan BMC yang dirancang, adapun pembuatan website menggunakan content management system dan database mysql, dan tahap implementasi dengan membeli hosting[9] dan domain[10] agar toko ini bisa dikunjungi secara online setiap saat dan oleh siapapun yang terhubung internet.

\section{METODE PENELITIAN}

\subsection{Jenis Penelitian}

Kegiatan penelitian yang dilakukan memilih jenis penelitian terapan atau dikenal dengan istilah reseach applied menggunakan pendekatan studikasus. kegiatan dimulai dengan mengidentifikasi permasalahan yang terdapat pada objek penelitian, berikutnya adalah menentukan cara penyelesaian atas permasalahan tersebut dengan cara membuat sistem usulan yang diharapkan dapat menyelesaikan permasalah yang teridentifikasi.

\subsection{Objek Penelitian}

Objek penelitian yang dijadikan sebagai tempat untuk mendapatkan data dan informasi terkait transaksi penjualan dalam penelitian ini adalah Kayra Nu Hijab yang beralamat di Jalan Tambaksari Raya, Tambaksari, Kecamatan Kuwarasan, Kabupaten Kebumen, Jawa Tengah, 54366.

\subsection{Sumber Data dan Metode Pengumpulan Data}

Sumber data pada penelitian ini diperoleh dari berbagai sumber yang berkaitan dengan penelitian yang penulis lakukan, yaitu :

a Data Primer bersumber dari proses wawancara dengan narasumber atau dari pihak toko yang dianggap memahami proses bisnis secara lengkap dan dapat memberikan informasi sebanyak mungkin sesuai dengan kebutuhan penelitian. Dan juga dapat menyediakan dokumen-dokumen bisnis yang digunakan seperti data nota penjualan, daftar produk dan harga, serta laporan penjualan, dan lainnya.

b Data Sekunder, berupa data pendukung untuk bahan referensi bagi peneliti dalam menyelesaikan penelitian ini, seperti studi literatur yang bersumber dari jurnal, prosiding dan buku terkait dengan topik penelitian.

Dalam penelitian ini, penulis membutuhkan data-data atau bahan materi yang berhubungan dengan topik penelitian. Ada beberapa metode pengumpulan data yang digunakan yaitu :

a Wawancara

Penulis melakukan wawancara terhadap pemilik toko yang bernama ibu Wiwit Sugiarsih, S.Pd., M.M. umur 41 Tahun, pendidikan terakhir Strata 2 Pendidikan Sains, beliau merupakan pemilik usaha toko Kayra Nu Hijab dan sudah berpengalaman usaha selama 5 tahun, selain menjadi pebisnis, beliau juga berprofesi sebagai tenaga pendidik atau guru yang mengajar mata pelajaran kimia di salah satu SMK Negeri di Kabupaten Kebumen.

b Observasi 
Penulis berkunjung ke toko secara langsung dan melakukan pengamatan atau observasi guna mendapatkan informasi dan memahami kegiatan traksaksi penjualan yang terjadi pada toko Kayra Nu Hijab.

c Analisis Dokumen

Penulis mengumpulkan dokumen keluaran dan masukan dari proses transaksi penjualan pada toko guna mendapatkan data dan informasi sebanyak mungkin, dokumen ini akan di analisa sesuai dengan proses bisnis yang ada pada toko.

d Studi Literatur

Penulis mencari dan mempelajari jurnal-jurnal penelitian atau prosiding terdahulu yang telah dipublikasi yang sesuai dengan topik penelitian ini, kemudian menjadikannya sebagai bahan referensi dalam melakukan penelitian ini.

\subsection{Metode Analisis Bisnis}

Metode analisis bisnis dalam penelitian ini menggunakan metode Business Model Canvas untuk mengidentifikasi model bisnis yang diterapkan. Dengan model ini, dapat memahami sebuah model bisnis secara garis besar. Konsep dari sebuah model bisnis harus ringkas, sesuai, dan mudah untuk dipahami. Business Model Canvas (BMC) merupakan gambaran atau rancangan business plan yang mewakili 9 blok penting, yang mana blok- blok tersebut saling berhubungan satu dengan yang lainnya untuk menghasilkan suatu model bisnis.

\subsection{Metode Pengembangan Bisnis}

Penulis menggunakan metode pengembangan sistem yang mengacu pada model Waterfall[11]. Secara konsep, metode waterfall dikerjakan secara berurutan dimulai dari tahap satu ke tahap lainnya. Metode ini merupakan metode dalam pengembangan sistem yang terdiri atas tahapan Analisis, Perancangan, Pengkodean, Pengujian dan Pengoperasian.

\subsection{Analisis Data}

Analisis proses bisnis berjalan yang terdapat terjadi pada obyek penelitian, dilakukan dengan menggambarkan urutan kegiatan transaksi penjualan berjalan secara terperinci, lalu kemudian digambarkan menggunakan activity diagram melalui software Microsoft Visio. Dan juga untuk identifikasi masalah sebab akibat dengan menggunakan diagram fishbone.

\subsection{Perancangan Sistem}

Perancangan sistem merupakan merancang suatu sistem secara detil berdasarkan hasil analisa dari sistem yang ada, sehingga menghasilkan model sistem usulan. Beberapa tools yang digunakan dalam melakukan perancangan sistem antara lain menggunakan diagram-diagram yang ada didalam Unified Modeling Language seperti : Use Case Diagram, Class Diagram, System Sequence Diagram, User Interface menggunakan Software Balsamiq Mockups, Interaction Flow Modeling Language dan Component Diagram.

Adapun dalam perancangan sistem menggunakan Content Management System (CMS) dari WordPress yang berbasis bahasa pemrograman PHP dengan plugin WooCommerce sebagai sistem e-commerce-nya dan beberapa plugin tambahan lainnya untuk menambah fungsionalitas dari website yang dibuat.

\subsection{Pengujian Program}

Dalam tahap pengujian program, penulis menggunakan pendekatan Blackbox Testing, dimana sistem diibaratkan seperti sebuah "blackbox", pengujian dilakukan berdasarkan hasil keluaran sistem pada saat sistem di compile atau pada saat entri data pada sistem, dengan hasil keluaran 0 (nol) pesan error (kesalahan). Dan test ini dilakukan oleh pembuat program secara langsung.

\subsection{Strategi Search Engine Optimization (SEO) dan Strategi Marketing}

Penulis menerapkan teknik Search Engine Optimization (SEO) untuk mempengaruhi posisi dari website yang dibuat di mesin pencari Google. Adapun teknik SEO yang dipakai dalam penelitian ini menggunakan pendekatan SEO On-page dengan bantuan plugin Yoast SEO. (a) Product, menyediakan produk dengan berbagai macam jenis dengan kualitas produk yang bersaing. (b) Price, menawarkan produk dengan harga yang terjangkau dengan produk sejenis. (c) Promotion, memasarkan produk melalui internet yang dapat menjangkau pelanggan, promosi penjualan berupa pemberian potongan harga untuk produk tertentu. (d) Place, menyediakan tempat yang strategis agar pelanggan bisa mengaksesnya dengan mudah. 
Halaman 40-48

available online at http://jom.fti.budiluhur.ac.id/index.php/IDEALIS/index

\section{HASIL DAN PEMBAHASAN}

\subsection{Analisa Masalah pada Sistem Berjalan}

Analisa sistem penjualan produk berjalan yang terjadi pada sistem ini digambarkan dalam bentuk activity diagram seperti yang terlihat pada Gambar 1.

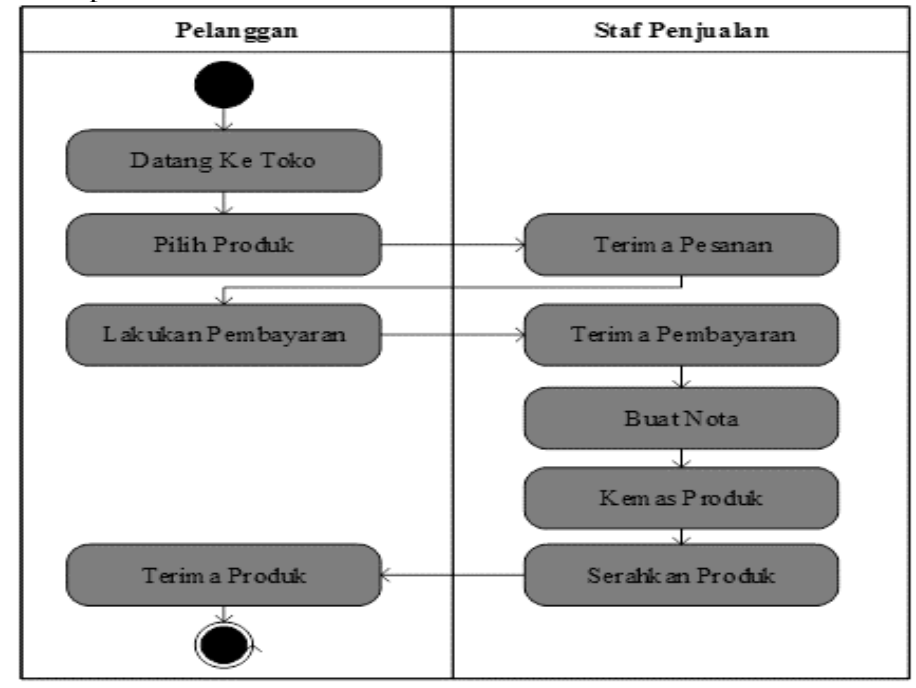

Gambar 1. Activity Diagram Penjualan Produk

Pada Gambar 1, Activity diagram penjualan produk, pelanggan datang ke toko, kemudian memilih produk yang akan dibeli, jika pelanggan ingin membeli maka lakukan pemesanan produk tersebut kepada staf penjualan, kemudian lakukan pembayaran. Staf penjualan akan menerima pembayaran dan membuat nota pembayaran. Berikutnya staf penjualan akan mengemas produk dan menyerahkannya kepada pelanggan.

\subsection{Analisa Bisnis Sistem Usulan}

Model bisnis yang diusulkan pada Kayra Nu Hijab digambarkan dalam bentuk business model canvas, dimana model ini terdiri atas 7 elemen seperti key partners, dan key activities, dan value proposition, dan customer relationship, dan customer segment, dan key resource, dan channels, dan cost structure and revenue streams, seperti yang terlihat pada Gambar 2.

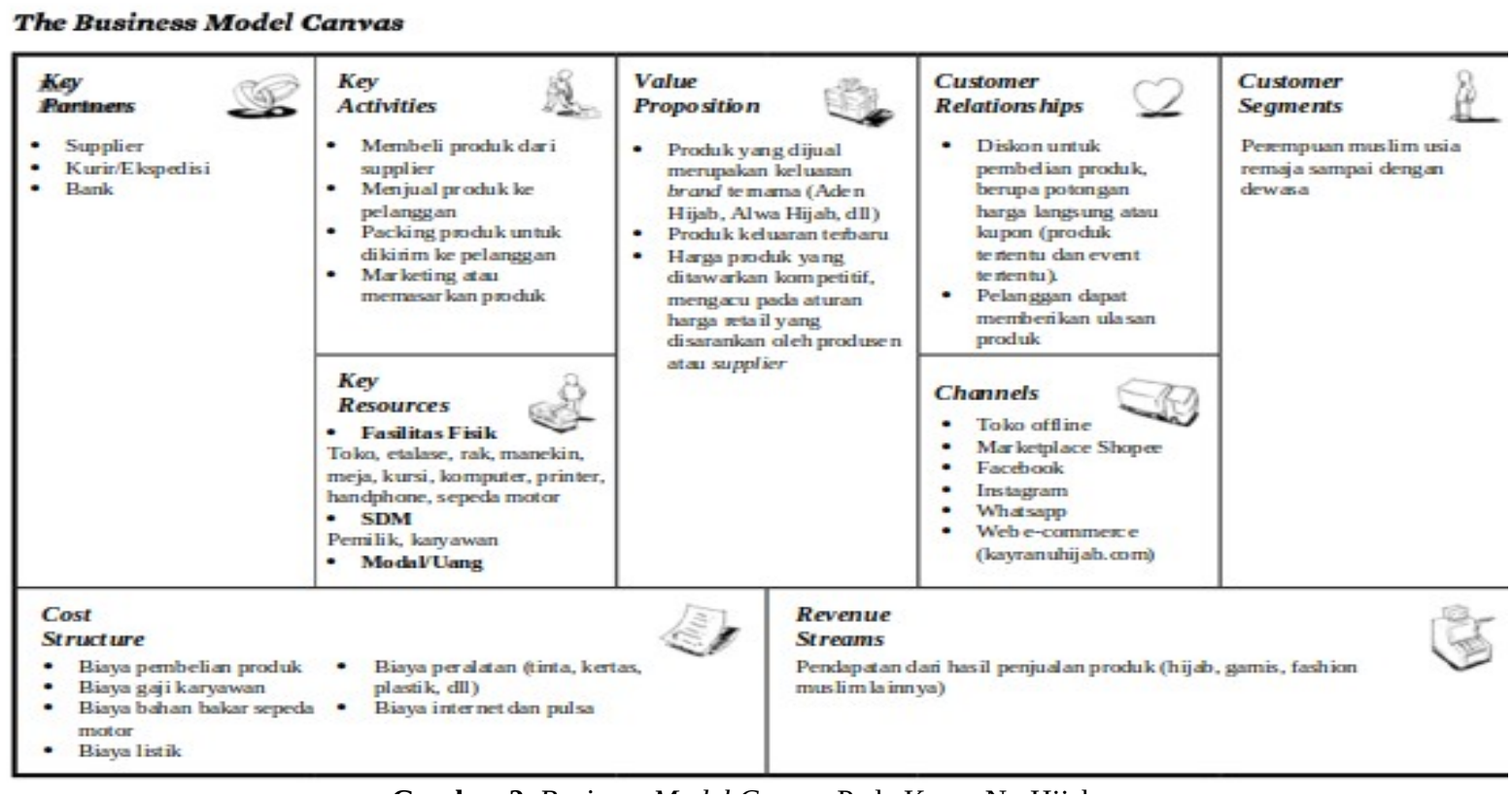

Pada Gambar 2, key partners Supplier sebagai pemasok produk yang dijual oleh Kayra Nu Hijab. Kurir atau ekspedisi sebagai pihak yang mengirimkan produk kepada pelanggan dan bank sebagai media transaksi 
available online at http://jom.fti.budiluhur.ac.id/index.php/IDEALIS/index

pembayaran. Key Activities antara lain membeli produk dari supplier, penjualan produk kepada pelanggan, pemasaran produk serta proses pengiriman produk ke pelanggan, dan seterusnya.

\subsection{Use Case Diagram}

Berikut merupakan Use Case Diagram Registrasi \& Login yang digabung dengan Use Case Diagram Pelanggan. Use Case Diagram Admin, Use Case Diagram Laporan. Seperti yang terlihat pada Gambar 3 dan Gambar 4. Digunakan untuk proses login ke sistem dan fungsionalitas sistem dari sisi pelanggan, sisi pemlik dan sisi Admin.

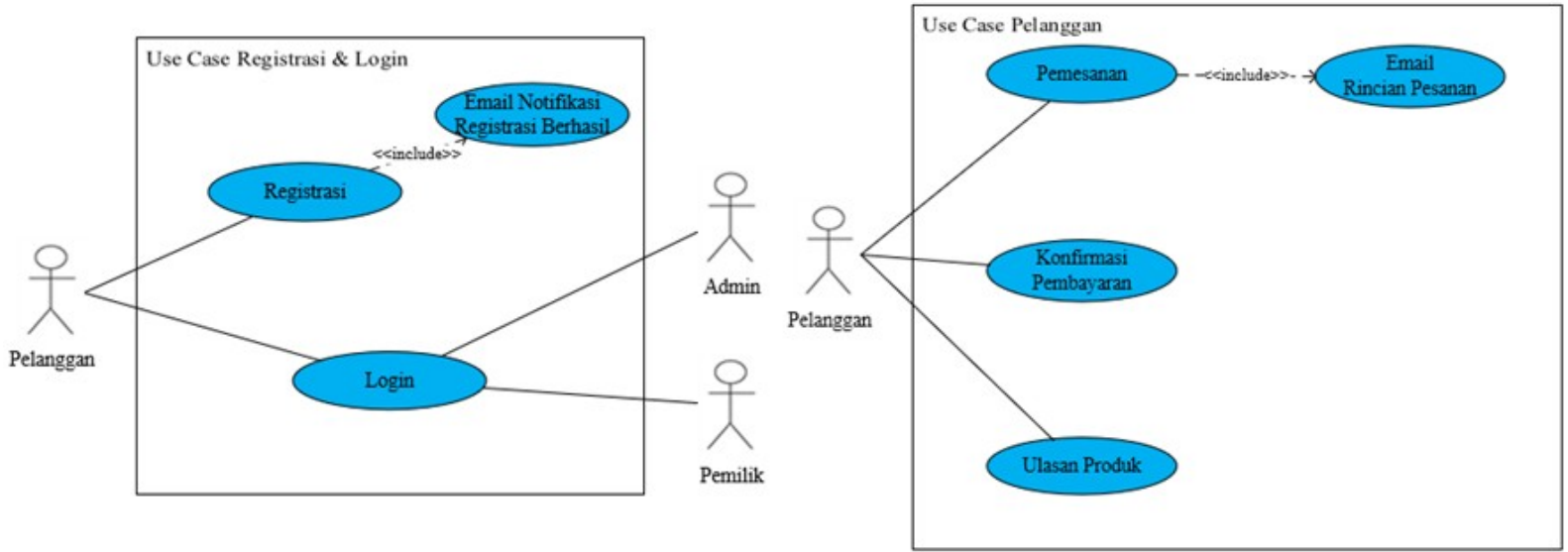

Gambar 3. Use Case Diagram Registrasi \& Login, Use Case Diagram Pelanggan

Pada Gambar 3. Proses login ke sistem digunakan oleh actor pelanggan, admin dan pemilik agar bisa mengakses fungsionalitas sistem ecommerce, dan actor pelanggan bisa melakukan pemesanan dan konfirmasi email, komfirmasi pembayaran dan memberi ulasan produk.
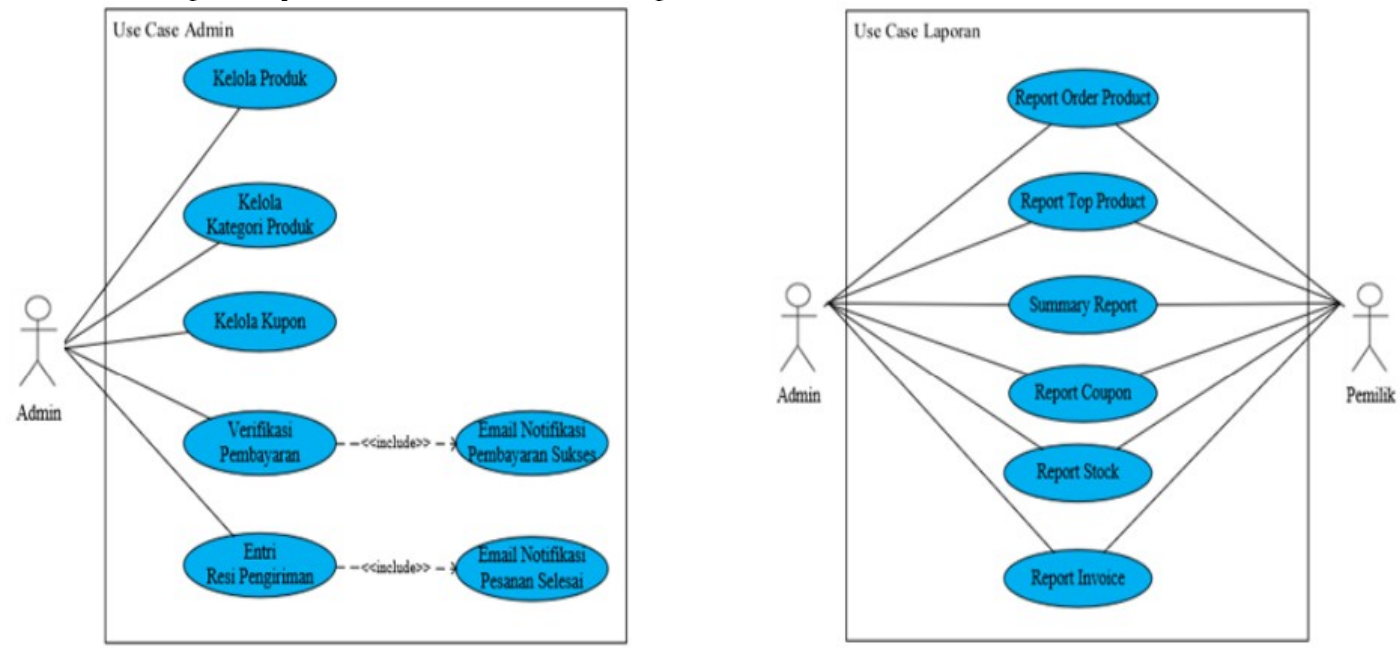

Gambar 4. Use Case Diagram Admin, Use Case Diagram Laporan

Pada Gambar 4. Admin mempunyai fungsionalitas kelola produk, kelola kategori produk, kelola kupon, verifikasi pembayaran dan entri resi pengiriman. Sedang kan pemilik mempunyai fungsionalitas report order product, report top product, summary report, dan lain-lain.

\subsection{Class Diagram}

Class Diagram yang dihasilkan dalam penelitian ini merupakan hasil keluaran dari tools Content Management System Wordpress dan ditambah dengan plugin woocommerce. seperti yang terlihat pada Gambar. 5. 
INDONESIA JOURNAL INFORMATION SYSTEM (IDEALIS)

Volume 5, Nomor 1, Januari 2022

ISSN 2684-7280 (online)

Halaman 40-48

available online at http://jom.fti.budiluhur.ac.id/index.php/IDEALIS/index
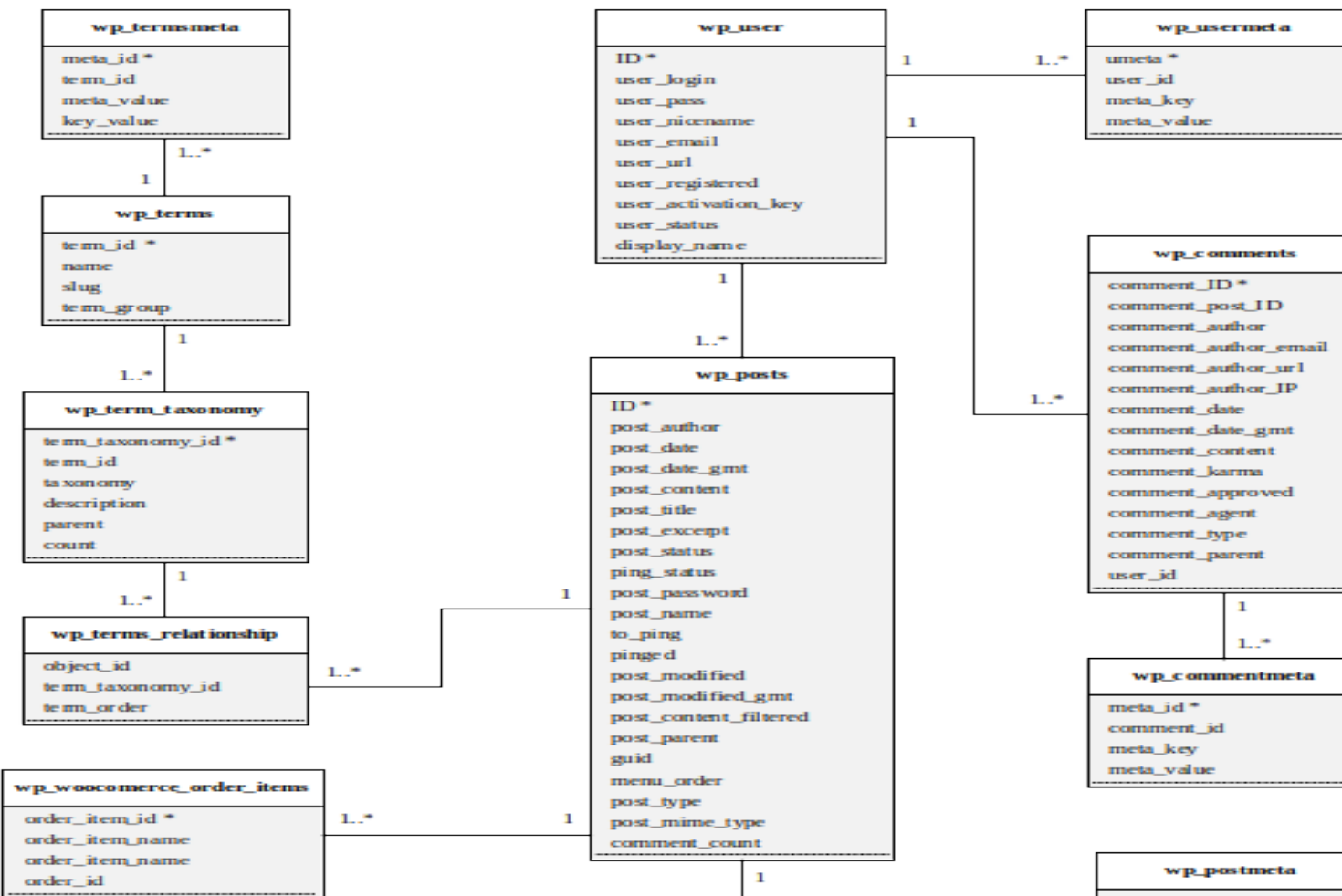

(1)

user_registered

(n) bey

display name

past nam

pinged

past_mocifified

post_mocifined gma

past_convent fil vered

post_paremt

gavid

meerm_arder

post_type

- Inime-type
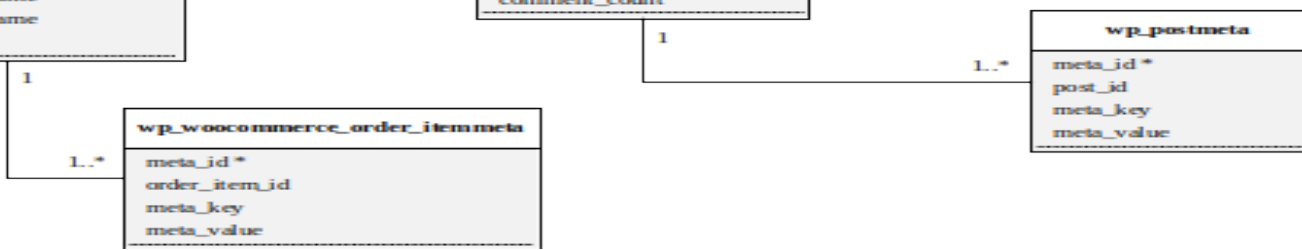

Gambar 5. Class Diaqram Wordpress dengan Woocommerce Plug-in.

Class diagram yang terbentuk seperti yang terlihat pada Gambar 5. Merupakan hasil keluaran dari content management system wordpress ditambah dengan woocommerce plugin. Diawal dengan melakukan proses instalasi pada tools wordpress dan melakukan setting sesuai dengan kebutuhan sistem, dan agar tampilan website bisa diakses secara online. Untuk fungsionalitas toko online menggunakan woocommerce dan melakukan setting sesuai dengan kebutuhan. Berdasarkan proses instalasi dan settingan yang dilakukan maka terbentuklah class diagram seperti yang terlihat pada gambar 5 .

\subsection{Hasil Keluaran Penelitian}

Hasil keluaran penelitian ini berupa sebuah website yang dapat membantu menyelesaikan permasalahan yang sudah teridentifikasi sebelumnya, website ini dapat diakses secara online melalui komputer atau smartphone dari para penggunanya. Berikut merupakan beberapa halaman website dari sistem penjualan ini.

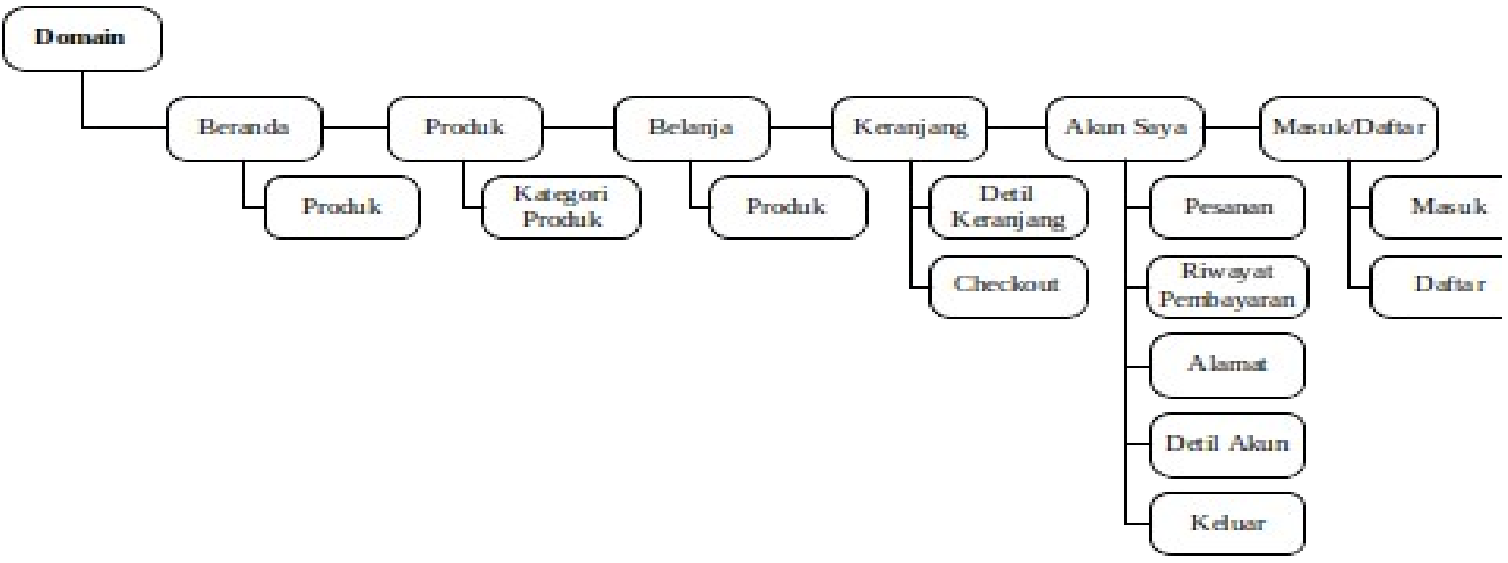

Gambar 6. Struktur Tampilan Front-end 
INDONESIA JOURNAL INFORMATION SYSTEM (IDEALIS)

Volume 5, Nomor 1, Januari 2022

ISSN 2684-7280 (online)

Halaman 40-48

available online at http://jom.fti.budiluhur.ac.id/index.php/IDEALIS/index

Pada Gambar 6. Merupakan struktur tampilan dari website kayra nu hijab tampilan depan atau front-end, daftar menu yang tampil disini berdasarkan fungsionalitas sistem yang digambarkan dalam use case diagram. Struktur tampilan ini di kelompokkan menjadi beranda, produk, belanja, keranjang, akun saya dan masuk/daftar.

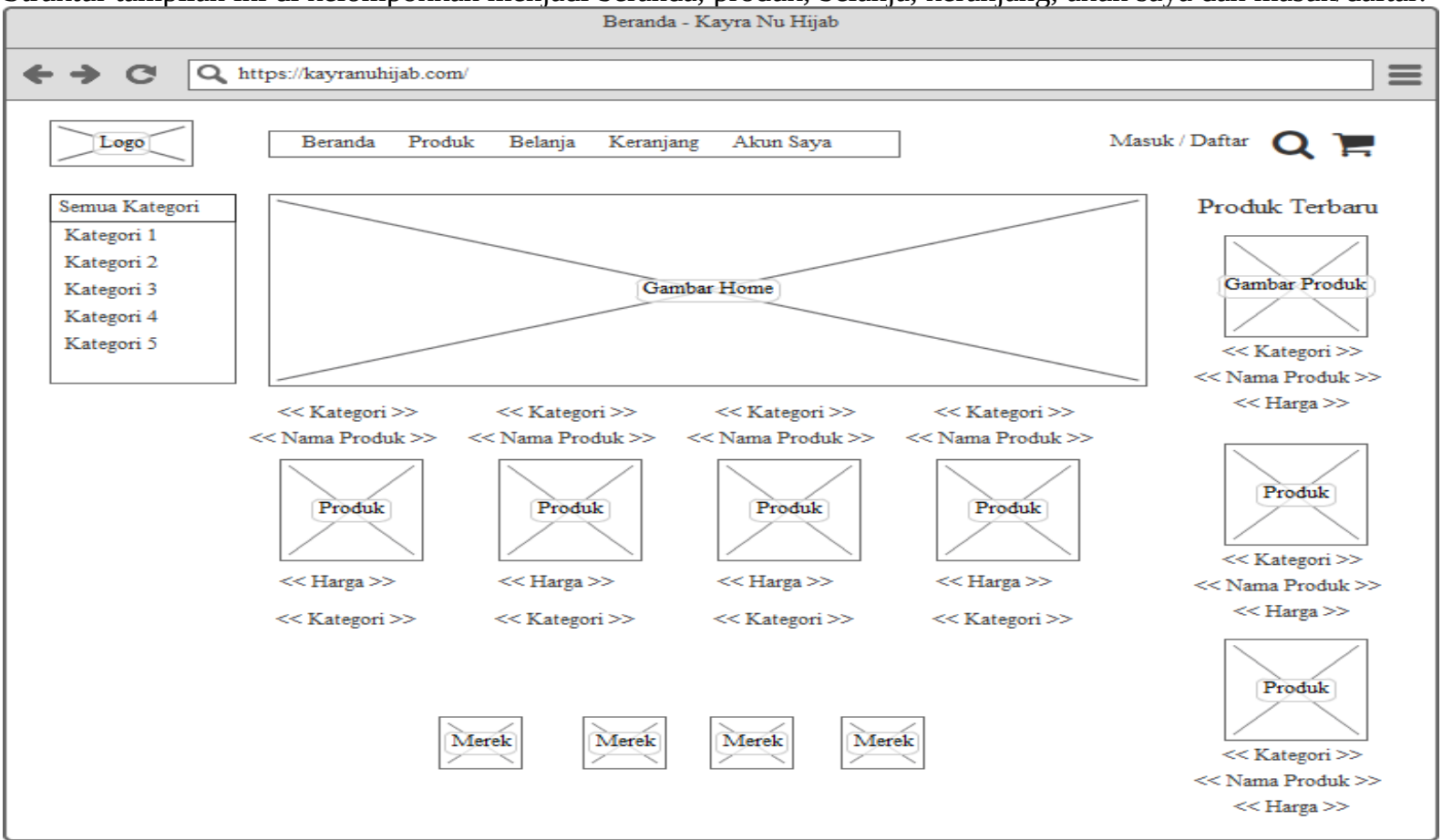

Gambar 7. Struktur Tampilan Rancangan Halaman Beranda

Sebuah website yang pertama kali dilihat pengunjungadalah halama pertama yang biasa disebut dengan beranda atau home page. Halaman ini sebisa mungkin dibuat menarik dan informatif agar menarik perhatian pengunjung. Pada penelitian ini tampilan dari halaman beranda seperti yang terlihat pada Gambar 7. Berisi produk-produk yang dijual, daftar menu dari sisi front end dan juga terdapat pilihan kategori produk. Hindari menampilkan semua produk pada halaman beranda karna akan membuat tampilan menjadi tidak rapi dan terlalu berlebihan. Dan terdapat fitur search yang dapat digunakan pengunjung untuk memudahkan pencarian produk di toko.

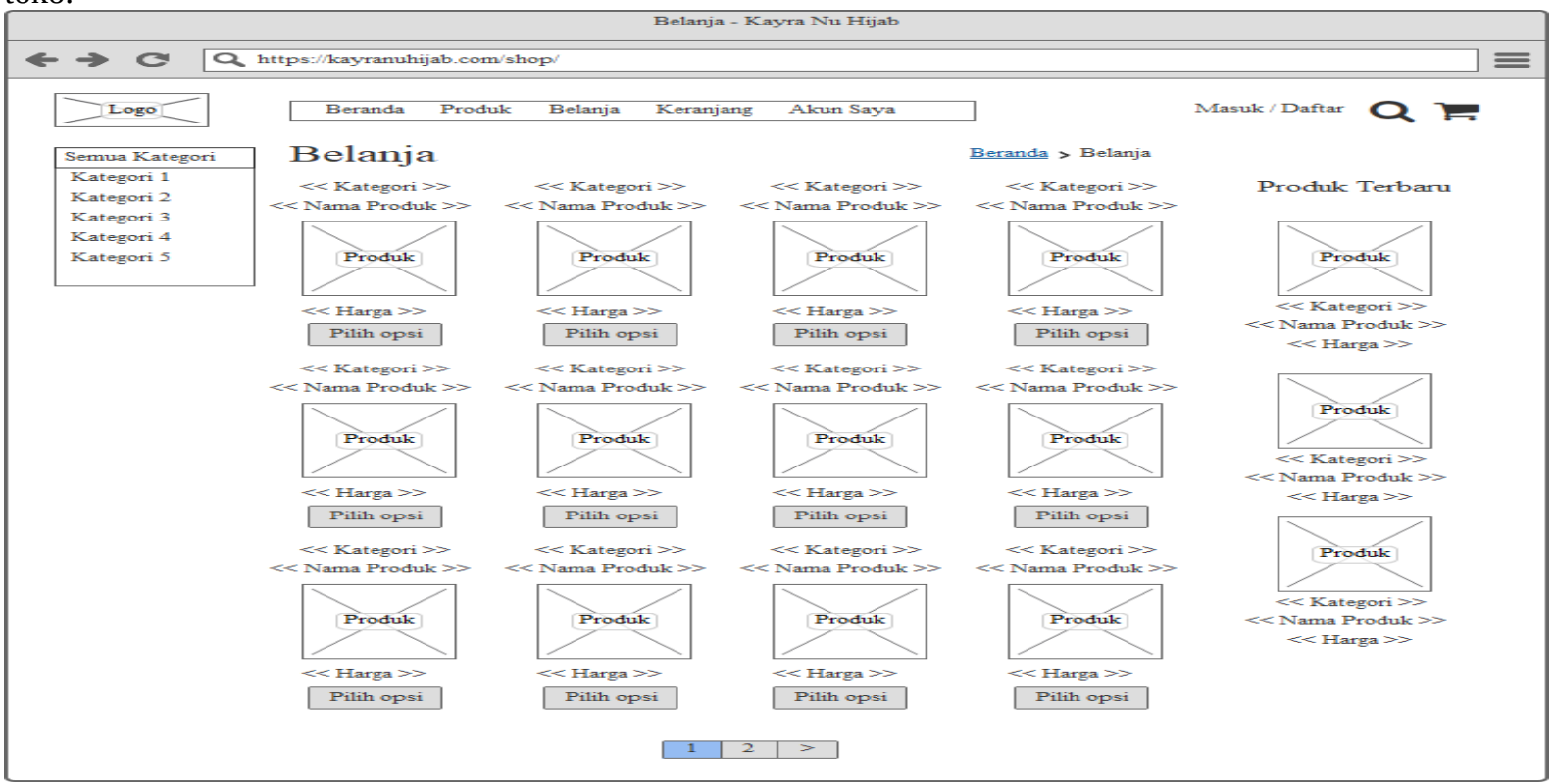

Gambar 8. Struktur Tampilan Rancangan Halaman Belanja

Rancangan halaman untuk pengunjung untuk melakukan belanja seperti yang terlihat pada Gambar 8. Di halaman ini pengunjung dapat melihat semua produk yang terdapat pada toko, setiap produk menampilkan image produk tersebut beserta dengan harga, jumlah stok beserda informasi detil tentang produk. Di halaman ini 
INDONESIA JOURNAL INFORMATION SYSTEM (IDEALIS)

Volume 5, Nomor 1, Januari 2022

ISSN 2684-7280 (online)

Halaman 40-48

available online at http://jom.fti.budiluhur.ac.id/index.php/IDEALIS/index

pengunjung bisa klik pada salah satu produk untuk melihat informasi lengkap dan bisa melakukan belanja untuk produk yang diinginkan.

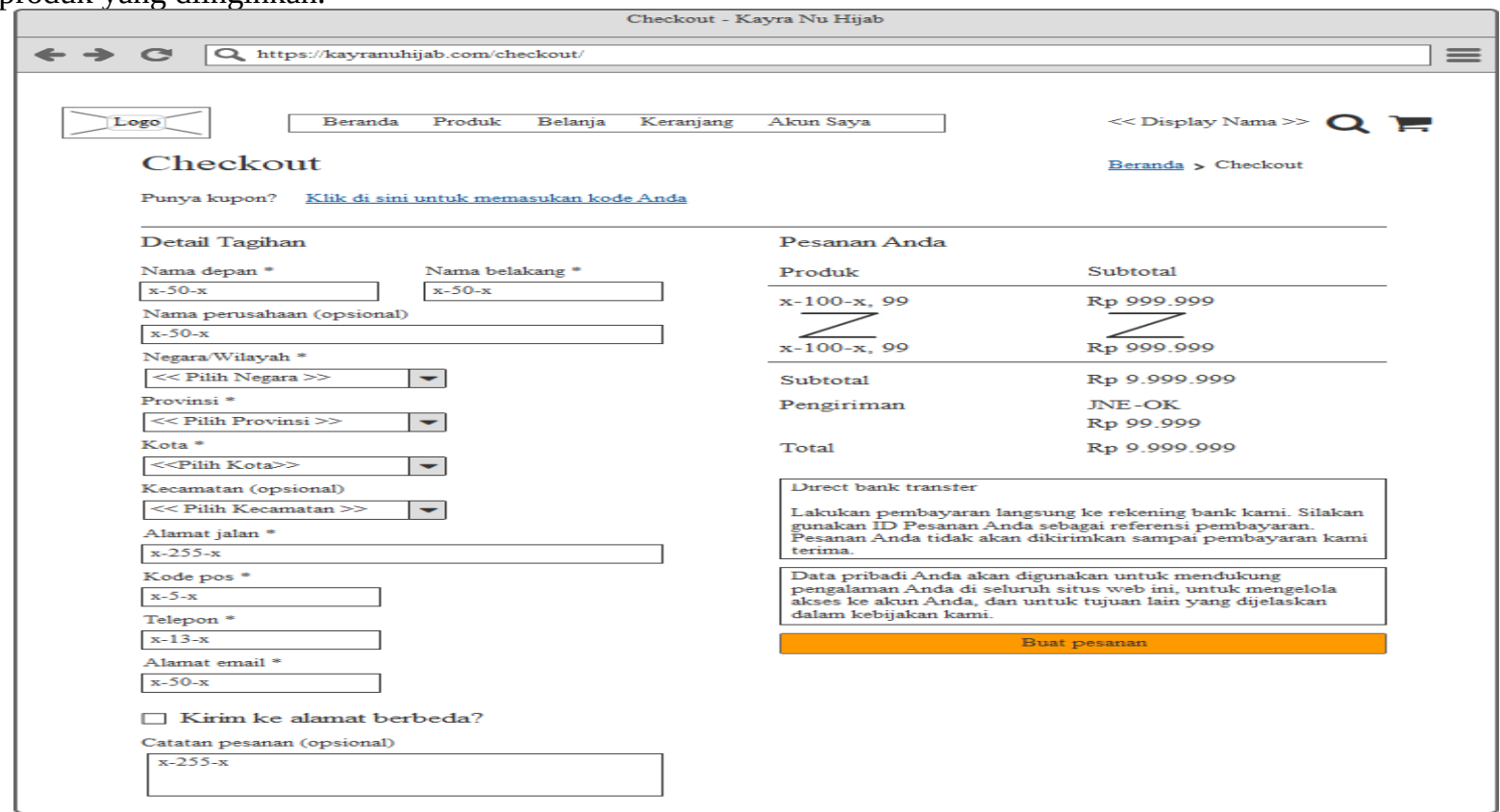

Gambar 9. Struktur Tampilan Rancangan Halaman Checkout

Setelah pengunjung sudah selesai berbelanda tahap berikutnya adalah masuk ke halaman checkout seperti yang terlihat pada Gambar 9. Di halaman ini pengunjung bisa melihat total harga pembayaran, besar kupon yang didapatkan beserta ongkos kirim, di halaman ini pengunjung juga bisa memasukkan alamat kirim. Adapun untuk proses pembayaran masih ditransfer langsung melalui no rekening toko. Dan harus melukukan konfirmasi pembayaran terhadap toko melalui website.

\section{KESIMPULAN}

Dalam penelitian ini dimulai tahap identifikasi masalah dan kemudian masuk ke tahap analisa dan pembahasan maka didapatkanlah kesimpulan sebagai berikut :

a Pemilik Kayra Nu Hijab dapat mengakses dan mendapatkan laporan-laporan penjualan yang tersedia dalam website ecommerce Kayra Nu Hijab.

b Pelanggan dapat dengan mudah mendapatkan informasi detil produk seperti harga produk, stok dan varian produk yang tersedia. Hal ini dikarenakan di dalam website Kayra Nu Hijab terdapat fitur informasi stok dan varian produk yang tersedia.

c Permasalahan promosi produk yang terbatas dapat di selesaikan dengan menggunakan website ecommerce Kayra Nu Hijab karena website sudah menggunakan teknik SEO agar mempermudah pencarian menggunakan mesin pencari.

d Website yang telah dibuat pada Kayra Nu Hijab dapat mengurangi kesalahan pada pembuatan laporan. karena pada sistem website Kayra Nu Hijab mempunyai menu-menu untuk melihat dan mengunduh laporan sesuai dengan periode yang diinginkan.

e Website Kayra Nu Hijab sudah menggunakan SEO On-Page, teknik ini akan membantu meningkatkan kemungkinan toko ini ditemukan melalui mesin pencari. Sehingga diharapkan makin banyak pengunjung yang melihat dan tertarik untuk melakukan pemesanan pada toko sehingga omset penjualan semaki meningkat.

\section{DAFTAR PUSTAKA}

[1] Y. Sudaryo and A. S. Nunung, Digital Marketing Dan Fintech Di Indonesia. Yogyakarta: Andi, 2020.

[2] R. Abdulloh, Trik Mudah Membuat CMS Website dari Nol. Jakarta: Elex Media Komputindo, 2016.

[3] S. Rahman, Mahir Wordpress 4 Plus. Jakarta: PT Elex Media Komputindo, 2015.

[4] N. A. Yati, E. Fernando, A. Rahim, T. Informatika, and S. D. Bangsa, "Perancangan Aplikasi E-Commerce pada Toko I ’ M Collection WTC Jambi,” J. Ilm. Process., vol. 12, no. 2, pp. 1021-1035, 2017.

[5] Syahriani, "Penerapan Sistem Informasi E-Commerce Pakaian dan Perlengkapan Bayi," J. Tek. Komput. AMIK BSI, vol. III, no. 2, pp. 77-82, 2017. 
INDONESIA JOURNAL INFORMATION SYSTEM (IDEALIS)

Volume 5, Nomor 1, Januari 2022

ISSN 2684-7280 (online)

Halaman 40-48

available online at http://jom.fti.budiluhur.ac.id/index.php/IDEALIS/index

[6] D. L. Fithri, A. P. Utomo, and F. Nugraha, "Pemanfaatan E-Commerce Populer Populer Untuk Optimalisasi Pemasaran Produk Pada Kube Bordir Kurnia Desa Demangan Kudus,” Simetris J. Tek. Mesin, Elektro dan Ilmu Komput., vol. 8, no. 2, pp. 819-824, 2017.

[7] F. M. Royan, Bisnis Model Kanvas Distributor: Memetakan Kinerja Optimal Distributor dan 30 Kesalahan yang Dilakukan. Jakarta: PT Gramedia Pustaka Utama, 2014.

[8] S. Mulyani, Metode Analisis dan Perancangan Sistem. Bandung: Abdi Sistematika, 2016.

[9] R. A. A. Riko Herwanto, Onno W. Purbo, Cloud Computing Manajemen dan Perencanaan Kapasitas. Yogyakarta: Andi, 2020.

[10] F. Husnan and J. Creativity, Membangun Website Interaktif dengan Blogger. Jakarta: PT Elex Media Komputindo, 2017.

[11] P. Widodo, Pudjo and Herawati, Menggunakan UML (Unified modeling Language). Bandung: Penerbit Informatika, 2011. 